\title{
CONGENITAL AND DEVELOPMENTAL MYOPIA
}

\author{
WAYNE G. WHITMORE \\ New York
}

\begin{abstract}
SUMMARY
Both hereditary and environmental factors are important in the interactive growth of the ocular tissues responsible for determining the refractive state of the eye. Myopia has a low prevalence in otherwise healthy children and is seen with an increased prevalence early in life in many systemic and ocular diseases. Predicting how refractive error will change in any individual child after birth or at any stage of ocular development is not possible at present, although, trends can be seen in longitudinal studies. In the disease states associated with an increased prevalence of myopia, information regarding the time of onset of myopia and the specific values for the refractive components, is lacking, so that underlying mechanisms of myopia development and whether the myopia is congenital or developmental, are not known. In adults, three different types of myopia can be characterised on the basis of clinical characteristics which have prognostic significance for ocular disease. The mechanisms of ocular growth that lead to these forms of myopia are not clear. At present, treatments to prevent or slow myopic progression have been marginally beneficial and of questionable value.
\end{abstract}

\section{NORMAL OCULAR GROWTH}

The development of ocular refraction is the result of a complex interaction between the growth of various ocular tissues. Corneal power, lens power, axial length, and anterior chamber depth (along with the respective indicies of refraction of the different media) combine to determine the refractive state of the eye. Statistical analysis has shown that significant correlations exist between the refractive components in emmetropic eyes of adults. Through infancy and childhood, these components undergo changes which result in the average refractive state changing from mild hyperopia to emmetropia. Since an overwhelming preponderance of emmetropia is seen in the adult population, there appears to be a developmental process (so-called 'emmetropisation') which results in

From: New York Hospital - Cornell University Medical Center, New York, New York

Correspondence to: Wayne G. Whitmore, M.D., 1001 Park Avenue, New York, New York 10028. growth of the refractive tissues toward emmetropia. Largely on the basis of experimental studies reviewed elsewhere, ${ }^{2,3}$ it is felt that emmetropisation is an active process and not just a passive independent growth of the ocular tissues. Environmental factors play a modifying role on the refractive state of the eye, with hereditary factors being the primary determinant of the ocular refractive state.

Table I shows the range of average measurements of the refractive components at birth, three years, and adulthood, as determined by the work of several authors in different studies reviewed by Curtin, ${ }^{1}$ and in a more recent study. ${ }^{4}$ Variations in these measurements among the different investigators can be accounted for by the different methods of calculation and measurement, population bias, and different definitions for age groups. Regardless of the variation in these measurements, it is obvious that a large amount of axial growth and corneal flattening takes place over the first few years of life, with the eye reaching virtually adult proportions after just a few years. The decreasing lens power along with the decreasing corneal power largely offsets the myopigenic axial growth of the eye such that the adult refraction becomes emmetropic rather than myopic.

\section{CLASSIFICATION OF MYOPIA}

From both a practical and theoretic standpoint, it is important to distinguish between the different types of myopia seen in humans. In physiologic myopia (also called 'simple' or 'refractive' myopia), there is a mismatch of the refractive components, all of whose values fall within their normal statistical ranges. Axial (or 'intermediate') myopia results from excessive enlargement of the pos-

Table I. Average Ocular Measurements for the Refractive Components in Random Samples of Healthy Patients

\begin{tabular}{lccc}
\hline & Newborn & Three-year-old & Adult \\
\hline Refraction & $0.4-2.6 \mathrm{D}$ & $0.6-3.0 \mathrm{D}$ & $-0.5-$ plano \\
Corneal power & $51-55 \mathrm{D}$ & $43-44 \mathrm{D}$ & $43-43.5 \mathrm{D}$ \\
AC depth & $2.4-2.9 \mathrm{~mm}$ & $3.3 \mathrm{~mm}$ & $3.5 \mathrm{~mm}$ \\
Axial length* & $16.7-17.5 \mathrm{~mm}$ & $22 \mathrm{~mm}$ & $22.8-23.5 \mathrm{~mm}$ \\
Lens power & $25-34 \mathrm{D}$ & $22 \mathrm{D}$ & $19-20 \mathrm{D}$ \\
\hline
\end{tabular}


terior segment and can usually be distinguished from refractive myopia by the clinical findings of temporal crescents on the optic discs, straightening of the retinal vessels, and fundus tessellation (retinal thinning). Axial myopia is associated with an increased risk of peripheral retinal degenerations, retinal detachments, and glaucoma. ${ }^{1}$ Pathologic myopia is a special form of axial myopia, defined clinically by the presence of a posterior staphyloma. In addition to being associated with the aforementioned complications of axial myopia, it is associated with the development of chorioretinal degeneration within the posterior staphyloma which usually leads to profound vision loss with advancing age. The distinction between these different forms of myopia may not be clear early in life, but with advancing age it usually becomes evident. An attempt to categorise myopia by the aforementioned types is useful not only in prognosis, but also in helping to understand the mechanisms responsible for the development of myopia which appear to be different in these different forms of myopia.

\section{MYOPIA PREVALENCE AND DEVELOPMENT}

The prevalence of myopia in the normal term newborn is probably between $4 \%$ and $6 \%$, although a literature review shows extremes of $1 \%$ and $25 \%{ }^{1}$ Only $1 \%$ to $2 \%$ of this myopia is high. Low myopia appears to resolve or decrease over the first few months of life. The incidence of myopia remains fairly stable over the first few years of life but shows an increase with advancing age through childhood. This increase is seen at about the time children are beginning school and this has implicated near work (and accommodation) as a cause for the development of myopia. Studies of the prevalence of myopia in adults show a wide variation (from $8 \%$ in Sweden to $52 \%$ in China) depending on the population and the adult age groups examined.

In the premature infant, studies of refractions show eyes to be more myopic or less hyperopic than the normal term infant. ${ }^{4,5}$ The prevalence of myopia appears to be greater with decreasing birthweight. ${ }^{4,6}$ The myopia of prematurity (excluding infants with retinopathy of prematurity) appears to be low in degree, is not associated with fundus changes typical of myopia, and usually regresses over the first year of life. It is uncertain how the refractive components change to account for this shift in refraction.

In utero, ocular growth proceeds according to poorly understood genetic factors. Environmental disturbances at this time (i.e. maternal illness) may upset the normal relationships between the refractive components resulting in the presence of myopia at birth or in conditions which lead to the development of myopia in early childhood. Congenital and developmental myopia can be seen in association with systemic disease, with ocular disease associated with systemic disease, with ocular disease alone, or as an isolated finding (Table II). The type of myopia (refractive or axial) or whether it is congenital or developmental, is not known in most of these diseases.
Table II. Congenital and Developmental Myopia

1. Associated with systemic disease (exclusive of other eye disease) albinism

Alport syndrome

cerebral palsy

Cornelia De Lang syndrome

Ehler's-Danlos syndrome

Fabray's disease

hereditary arthro-ophthalmopathies

homocystinuria

Marfan syndrome

Noonan syndrome

Pierre-Robin syndrome

Riley-Day syndrome (familial dysautomonia)

trisomy $21,22,16,17$, and 13 (?)

2. Associated with ocular disease

a) without systemic disease

achromatopsia (rod monochromacy, blue cone

monochromacy)

cataract

choroideraemia

coloboma

corneal scarring or opacification

congenital stationary night blindness

ectopia lentis

familial exudative vitreoretinopathy

fundus flavimaculatus

glaucoma

gyrate atrophy

Jansen's vitreoretinal degeneration

keratoconus

microcornea

microphthalmos (nanophthalmos)

microphakia

myelinated nerve fibres

nystagmus

optic nerve hypoplasia

ptosis

retinitis pigmentosa

retinopathy of prematurity

vitreous haemorrhage

Wagner's vitreoretinal degeneration

b) associated with systemic disease

albinism

cataract - Alport syndrome, Fabray's disease, congenital rubella, Marfan syndrome, homocystinuria,

artho-ophthalmopathies

congenital external ophthalmoplegia

corneal opacity - Fabray's disease, hereditary arthro-ophthalmopathies

ectopia lentis - dwarfism, Ehler's-Danlos

syndrome homocystinuria, Marchesani syndrome,

Marfan syndrome,

arthro-ophthalmopathies

glaucoma - homocystinuria, congenital rubella, microphthalmia, arthro-ophthalmopathies

lenticonus - Alport syndrome

keratoconus - homocystinuria, Marfan syndrome,

Marchesani syndrome, Laurence-Moon-BardetBiedl syndrome, trisomy 21 ,

Noonan syndrome

microphakia - Marchesani syndrome,

Marfan syndrome microphthalmia - arthro-ophthalmopathies retinopathy - congenital rubella, arthro-ophthalmopathies, Ehler's-Danlos syndrome, ROP (?)

spherophakia - Marfan syndrome

vitreoretinal degenerations - Stickler syndrome, spondyloepiphyseal dysplasia

3. Isolated myopia (no other known pre-existing eye or systemic disease)

a) refractive myopia ('simple', 'physiologic' or 'correlation' myopia)

b) axial myopia ('intermediate' myopia)

c) pathologic myopia ('degenerative' myopia) 
To determine the aetiology of myopia, it is logical to look for common characteristics among the diseases in which it has an increased prevalence. Unfortunately, because of the variable frequency with which myopia presents in the different diseases and our almost total lack of information with regard to the actual mesurements of the refractive components of these eyes at any stage in development, it is difficult to form any conclusions at the present time. There are, however, several conditions which appear to simulate the deprivation myopia seen in nonhuman primates ${ }^{7}$ and can be classified as developmental forms of axial myopia. Uniocular visual deprivation in neonates with congenital cataract, ${ }^{8,9}$ ptosis, ${ }^{10}$ corneal scarring, ${ }^{11,12}$ myelinated nerve fibres in the retina, ${ }^{13,14}$ vitreous haemorrhage, ${ }^{15}$ and optic nerve hypoplasia, ${ }^{16,17}$ all show a trend toward axial elongation and myopia in the involved eye. Myopia as a result of astigmatism induced by hemangiomas of the eyelid may also have a similar mechanism. ${ }^{18}$ Cataract, ptosis, vitreous haemorrhage, and corneal scarring with onset in adulthood have not been reported to cause myopia. As in experimental studies, it appears that the earlier the onset of the visual deprivation in ocular development, the greater the axial elongation. ${ }^{11}$ It is uncertain how the mechanisms involved in this form of developmental myopia relate to bilateral myopia where there is no obvious opacification of the ocular media.

\section{THEORIES AND TREATMENTS}

Although it has been shown that there is a higher risk of myopic progression in children with myopic fundus changes, with intraocular pressures above $16 \mathrm{~mm} \mathrm{Hg}$, and with myopia greater than or equal to 3.00 diopters, ${ }^{19}$ for the most part it has been assumed, from the increasing prevalence of myopia seen with age in children, that myopia tends to progress. This may not, however, be the case for any individual child. Unfortunately, this means that some children will be treated for myopic progression unnecessarily. This has begged caution with regard to treatment since the morbidity of myopia is relatively low.

Nonsurgical methods of treating the progression of myopia have lately focused in several areas; on reducing ocular accommodation by medications or by the use of bifocal spectacles; on reducing scleral stress by lowering intraocular pressure; and on flattening the cornea through the use of rigid contact lenses.

The first of these forms of treatment is a consequence of the observation that a visual experience requiring focusing at near over long periods of time, is associated with a higher prevalence of myopia. The mechanism by which prolonged accommodation, convergence, and/or near visual input over long periods of time might cause the increased prevalence of myopia seen in humans with a visual experience of this nature, is still debated. Experimental deprivation myopia in animals suggests that retinal image focus (through biochemical or neurochemical mechanisms) may be a factor in the development of myopia ${ }^{20}$ but mechanical factors (i.e. the physical forces on and within the eye from ocular accommodation and convergence) have been the focus of attention for a good part of this century. Coleman has postulated an aqueous-vitreous pressure gradient (pressure greater in the vitreous) during accommodation, ${ }^{21}$ which presumably could result in increased stress on the sclera with consequent stretching and elongation of the globe. Supporting the theory that the mechanical influence of accommodation results in myopia is the fact that atropine has been shown to slow or arrest the progression of low grade myopia in adolescents. ${ }^{22,23}$ The effect is not marked and may diminish over time after atropine has been stopped. Cyclopentolate and tropicamide appear to be ineffective. ${ }^{1}$

Without any cycloplegic medications, a recent randomised study in myopic schoolchildren showed that the progression of myopia could not be stopped by using bifocals or removing myopic spectacles for reading or near work. ${ }^{24}$ On the contrary, myopic progression appeared to be less in the reference group who wore their full myopic correction at all times (although this finding was not statistically significant). A faster progression of myopia was seen in all three treatment groups in those children who spent a greater amount of time reading or at near work. This latter finding, as well as the failure of bifocal correction to slow the progression of myopia, was also reconfirmed by Jensen. ${ }^{19}$

The importance of scleral stress and intraocular pressure in the development of ocular refraction has been reviewed by Pruett. ${ }^{25}$ The increased prevalence of myopia seen in juvenile glaucoma as well as the increased prevalence of glaucoma associated with pathologic myopia, emphasises this relationship. In a recent controlled study using schoolchildren aged 9-12 years, timolol maleate was given over a two-year period. ${ }^{19}$ Despite a significantly lower intraocular pressure in the treated group of between 2 and $3 \mathrm{~mm} \mathrm{Hg}$, no significant benefit was seen with regard to slowing the progression of myopia. The treatment period and the degree of intraocular pressure lowering were relatively small, but the absence of any trend whatsoever, is discouraging.

Van Alphen has postulated that the ciliary muscle and choroid have a baseline tonus, independent of accommodation, which mitigates the effect of intraocular pressure on the stretching of sclera normally seen with ocular development. ${ }^{26}$ According to his theory, the autonomic nervous system plays a key role in adjusting the baseline tonus to achieve emmetropia and he suggests that stress (i.e., sympathetic nervous stimulation from performance anxiety in schoolchildren) leads to a decrease in this tonus, allowing the full force of intraocular pressure to be transmitted to the scleral wall with the consequent development of ocular enlargement and myopia. That anxiolytic medications might prevent myopia development or slow myopic progression is intriguing but there has been no research along these lines to date.

Studies dealing with the effect of rigid contact lenses on the prevention of myopic progression can be summarised by saying that most of the effect seen on slowing the pro- 
gression of myopia is due to corneal flattening. ${ }^{27,28}$ Any effect on reducing axial growth, if it exists, might be explained by the differences in the clarity of focus in the peripheral retina between these two different methods of optical correction. Peripheral retinal defocus induced by spectacle correction, may result in ocular expansion and myopia development through mechanisms similar to those seen in deprivation myopia in animals. ${ }^{20}$

Scleral reinforcement is a surgical treatment reserved for pathologic myopia and should probably only be used in patients before the onset of visual deterioration from myopic macular degenerative changes. The object of the treatment is to prevent further elongation of the globe with its attendent chorioretinal thinning and atrophy. Unfortunately, although there are many reports attesting to its efficacy, the only long-term controlled study (using fellow eyes for the control) with axial length measurements, failed to demonstrate the ability of this procedure to prevent further axial elongation of the globe ${ }^{29}$ Periscleral collagen grafts, although they maintain their postion over long periods of time and may appear to have some reinforcing effect, do not appear to benefit the recipients. ${ }^{30}$ It has been suggested that different periscleral graft materials may be more efficacious ${ }^{31}$ but controlled studies to determine whether or not this is the case have not been done.

Various techniques of surgically implanting different collagenous materials in the sub-Tenon's space to augment existing sclera in progressive and pathologic myopia, have recently been popular in the Soviet Union. ${ }^{32,33}$ Despite the ease with which these procedures can be done when compared with the conventional scleral reinforcement operation, they may still have severe complications. ${ }^{34}$ There do not appear to be any controlled studies regarding the efficacy of these procedures from review of the English abstracts of these Russian publications.

Recent experimental studies show a modulatory effect of cryotherapy or laser treatment of anterior retina on the growth of the eye. ${ }^{35}$ The treatments, which avoid ciliary body and have no effect on intraocular pressure, appear to slow ocular growth (overall eye size, as well as lens, and cornea). These results stress the importance of the retina (and possibly choroid) in the normal growth of the eye. It is too early to say whether this form of treatment will have any clinical application in humans.

\section{CONCLUSION}

The fact that refractive and axial myopia, with the exception of pathologic myopia, are not vision threatening conditions, begs caution with regard to aggressive measures in preventing their progression. Known and potentially unknown long-term side effects of medications, probably outweigh any potential benefits that their use may have in children at the present time. Spectacles, contact lenses and external environmental manipulations are certainly more benign, but have so far been ineffective.

The biochemical processes that result in the differential and inter-related growth of the tissues which determine the refractive state of the eye are unknown at present. Recent experimental studies, however, suggest that dopamine metabolism may be important in myopia development. ${ }^{36,37}$ Retinal levels of dopamine have been shown to decrease significantly in form-deprivation myopia in both chickens and monkeys when compared to control eyes. When apomorphine, a dopamine agonist, is instilled in form-deprived eyes of both the chick and the monkey, it prevents the development of axial myopia.

Continued experimental research along these lines, will certainly improve our understanding of myopia development and, hopefully, lead to ways in which we can control ocular growth and modulate ocular refraction. It is in infancy and during childhood, that we will have the best chance at modulating the growth of the eye and in preventing the development and progression of myopia.

\section{REFERENCES}

1. Curtin BJ: 'The Myopias', Harper \& Row, Publishers, Philadelphia 1985 pp. 17-27, 72-97, 169-175.

2. Whitmore WG: The etiology of myopia. Curr On Ophthalmol 1991, 2: 72-7.

3. Schaeffel F and Howland HC: Mathematical model of emmetropization in the chicken. J Opt Soc Am 1988, 12: 2080-86.

4. Gordon RA, and Donzis PB: Refractice development of the human eye. Arch Ophthalmol 1985, 103: 785-9.

5. Banks MS: Infant refraction and accommodation. In Sokol S (Ed.), 'Electrophysiology and Psychophysics: Their use in Ophthalmic Diagnosis', Intl Ophth Clinics 1980, 20: 205-232.

6. Graham MV and Gray OP: Refraction in premature babies' eyes. Br Med J 1963, 5343: 1452-6.

7. Raviola $\mathrm{E}$ and Wiesel TN: An animal model of myopia. $N$ Engl J Med 1985, 312: 1609-15.

8. Von Noorden GK and Lewis RA: Ocular axial length in unilateral congenital cataracts and blepharoptosis. Invest Ophthalmol Vis Sci 1987, 28: 750-2.

9. Johnson CA, Post RB, Chalapa LM, Lee J: Monocular deprivation in humans: a study of identical twins. Invest Ophthalmol Vis Sci 1982, 23: 135-8.

10. Hoyt CS, Stone RD, Fromer C, Billson FA: Monocular axial myopia associated with neonatal eyelid closure in human infants. Am J Ophthalmol 1981, 91: 197-200.

11. Gee SS and Tabbara KF: Increase in ocular axial length in patients with corneal opacification. Ophthalmol 1988, 95: 1276-8.

12. Twomey JM, Gilvarry A, Restori M, Kirkness CM, Moore AT, Holden AL: Ocular enlargement following infantile corneal opacification. Eye 1990, 4: 497-503.

13. Holland PM and Anderson B: Myelinated nerve fibers and severe myopia. Am J Ophthalmol 1976, 81: 597-601.

14. Summers CG, Romig L, Lavoie JD: Unexpected good results after therapy for anisometropic amblyopia associated with unilateral peripapillary myelinated nerve fibers. $J$ Ped Ophthalmol Strabismus 1991, 28: 134-36.

15. Miller-Meeks MJ, Bennet SR, Keech RV, Blodi CF: Myopia induced by vitreous haemorrhage. Am J Ophthalmol 1990, 109: 199-203.

16. Weiss A. and Ross EA: Axial myopia in eyes with optic nerve hypoplasia. Invest Ophthalmol Vis Sci 1990, Arvo abstracts, 31: 277.

17. Egbert JE and France TD: Myopia associated with optic nerve hypoplasia in humans. Invest Ophthalmol Vis Sct 1990, ARVO Abstracts, 31: 277.

18. Robb RM: Refractive errors associated with hemangiomas 
of the eyelid and orbit in infancy. Am J Ophthalmol 1977, 83: $52-8$.

19. Jensen H: Myopia progression in young schoolchildren: A prospective study of myopia progression and the effect of a trial with bifocal lenses and beta blocker eye drops. Acta Ophthalmol 1991, 200 (supplement): 1-78.

20. Wallman J: Retinal influences on sclera underlie visual deprivation myopia. In, 'Myopia and the Control of Eye Growth', Ciba Foundation Symposium 155, Wiley and Sone, New York, 1990, pp. 126-34.

21. Coleman DJ: Unified model for accommodation. Am J Ophthalmol 1970, 69: 1063-9.

22. Brodstein RS, Brodstein DE, Olsen RJ, Hunt SC, Williams RR: The treatment of myopia with atropine and bifocals. Ophthalmol 1984, 91: 1373-8.

23. Dyer JA: Role of cycloplegics in progressive myopia. Ophthalmol 1979, 86: 692-6.

24. Parssinen O, Hemminki E, Klemetti A: Effect of spectacle use and accommodation on myopic progression: final results of a three-year randomised clinical trial among schoolchildren. Br J Ophthalmol 1989, 73: 547-51.

25. Pruett RC: Progressive myopia and intraocular pressure: what is the linkage? Acta Ophthalmol 1988, 66 (Supplement 185): 117-27.

26. Van Alphen GW: Emmetropization in the primate eye. In 'Myopia and the Control of Eye Growth', Ciba Foundation Symposium 155, Wiley and Sons, New York, 1990, pp. 115-125.

27. Goldschmidt E: Myopia in humans: can progression be arrested? In 'Myopia and the Control of Eye Growth', Ciba Foundation Symposium 155 Wiley and Sons, New York, 1990, pp, 222-9.

28. Grosvenor T and Goss DA: The role of bifocal and contact lenses in myopia control. Acta Ophthalmol 1988, 66 (Supplement 185): 162-6.
29. Curtin BJ and Whitmore WG: Long-term results of scleral reinforcement surgery. Am J Ophthalmol 1987, 103: 544-8.

30. Whitmore WG and Curtin BJ: Scleral reinforcement. Two case reports. Ophthalmic Surg 1987, 18: 503-5.

31. Whitmore WG, Harrison W, Curtin BJ: Scleral reinforcement in rabbits using synthetic graft materials. Ophthalmic Surg 1990, 21: 327-30.

32. Sergienko NM, Lemziakov GG, Denisiuk NB, Radokhleb OM: Sposob khirurgicheskogo lecheniia progressiruiushchei, vysokoi i oslozhnennoi blizorukosti (A method of surgical treatment of progressive and complicated myopia). Oftalmol Zh 1990, 3: 157-60.

33. Bushueva NN: Otdalennye rezul'taty razlichnykh metodov skleroukrepliaiushchikh operatsii u detei i podrostkov, stradaiushchikh progressiruiushchei blizorukost'iu (The late results of different methods of sclera-reinforcing operations on children and adolescents suffering from progressive myopia). Oftalmol Zh 1989, 4: 194-8.

34. Es'kova NK, Kiseleva OA, Morozova, IV: Sluchai iz praktiki. Sluchai dvukhstoronnei otsloiki setchatki posle operatsii sklero-plastiki (A clinical case. A case of bilateral retinal detachment after scleroplasty). Vestn Oftalmol 1990, 106: $60-1$.

35. Whitmore WG and Curtin BJ: Inhibition of ocular growth in rabbits with transcleral cryotherapy of anterior retina. Invest Ophthalmol Vis Sci 1990, ARVO Abstracts, 31: 132.

36. Iuvone PM, Tigges M, Stone RA, Lammbert S, Laties AM: Effects of apomorphine, a dopamine receptor agonist, on ocular refraction and axial elongation in a primate model of myopia. Invest Ophthalmol Vis Sci 1991, 32: 1674-7.

37. Stone AS, Lin T, Iuvone PM, Laties AM: Postnatal control of ocular growth: dopminergic mechanisms. In, Myopia and the Control of Eye Growth, Ciba Foundation Symposium 155, Wiley and Sons, New York, 1990 pp. 44-57. 